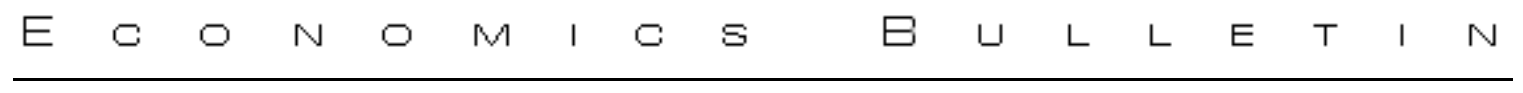

\title{
Welfare Analysis in a Schumpeterian Growth Model with Capital
}

\author{
Marcus Hagedorn \\ University of Frankfurt
}

\author{
Ashok Kaul \\ Gutenberg University Mainz and IEW, University of \\ Zürich
}

\author{
Volker Reinthaler \\ Universitat Pompeu Fabra
}

\begin{abstract}
In this note we compare the laissez-faire steady-state solution in the Howitt and Aghion (1998) model to the social optimum. The analysis offers several new insights in comparison to the welfare analysis in Aghion and Howitt (1992). We find various new distortions between private and optimal solution. First, a monopoly distortion effect generates too little capital accumulation in the private solution because households' gross return per unit of capital will be lower than in the social optimum due to monopoly power. Second, a cost-benefit gap effect leads to excessive research in the private solution because the planner is interested in the average technology whereas the private researcher is interested in the leading-edge technology. Third, we decompose the well-known intertemporal spillover effect into three subeffects and clarify why the planner does not consider other factors than the interest rate to discount gains from innovation.
\end{abstract}

Financial support through the RTN network "Product Markets, Financial Markets and the Pace of Innovation in Europe" of the European Union is gratefully acknowledged.

Citation: Hagedorn, Marcus, Ashok Kaul, and Volker Reinthaler, (2007) "Welfare Analysis in a Schumpeterian Growth Model with Capital." Economics Bulletin, Vol. 15, No. 7 pp. 1-6

Submitted: October 18, 2006. Accepted: March 24, 2007.

URL: http://economicsbulletin.vanderbilt.edu/2007/volume15/EB-06O40010A.pdf 


\section{Introduction and Model Description}

In this note, we compare the laissez-faire steady-state solution to the social optimum in Howitt and Aghion (1998). The analysis offers new insights in comparison to Aghion and Howitt (1992).

Recall the basic structure of the Howitt and Aghion (1998) model. Firms in the competitive final good sector produce their good using the fixed labor supply $L$ of the economy and the intermediate goods $x_{i t}, i \epsilon[0,1]$ according to the production function $Y_{t}=\int_{0}^{1} A_{i t} F\left(x_{i t}, L\right) d i$, where $x_{i t}$ is the factor input of intermediate input $i$ and $A_{i t}$ is the corresponding productivity parameter in sector $i$ in period $t$. The monopolistic intermediate good sectors produce intermediate goods using capital only: $x_{i t}=\frac{K_{i t}}{A_{i t}} \forall i$. There is a different research sector for each intermediate good. Firms in the research sector attempt to discover the next generation of the intermediate good. If in sector $i N_{i t}$ is spent on research, innovation occurs with Poisson probability $\phi_{i t}=\lambda n_{i t}$, where $n_{i t}=\frac{N_{i t}}{A_{t}^{\text {max }}} \forall i, \lambda$ is the productivity of research, $A_{t}^{\max } \equiv \max \left\{A_{i t} \mid i \epsilon[0,1]\right\}$ is the "leading-edge" productivity parameter and $n_{i t}$ is the productivity adjusted research intensity.

Innovation has two effects, one is sector specific, the other is aggregate. The sector specific effect improves the existing intermediate good $i$. The improved intermediate good enters the production of the final good with higher productivity: $A_{i t}$ jumps to $A_{t}^{\max }$. The successful innovator is granted a patent which gives him the right to produce the intermediate good until he is replaced by a new innovator. The second, aggregate effect of innovation is a technology spillover effect. Each innovator can build on the stock of technology as embodied in the leading-edge technology $A_{t}^{\max }$, independent of the technology in its corresponding intermediate good sector, $A_{i t}$. Since there is a continuum of intermediate goods, $A_{t}^{\max }$ will grow continuously at a rate proportional to the aggregate rate of innovation $\lambda n_{t}$, where $n_{t}$ is the aggregate research input and $\sigma$ is the factor of proportionality. The growth rate of $A_{t}^{\max }$ will be $g_{t} \equiv \frac{\dot{A}_{t}^{\max }}{A_{t}^{\max }}=\sigma \lambda n_{t}$.

There is a representative infinitely lived household that has a utility function with constant elasticity of intertemporal substitution. He makes an intertemporal consumption-savings decision subject to a standard budget constraint. The household side can be summarized by the familiar Euler equation: $\frac{\dot{C}}{C}=\frac{r(.)-\rho}{\varepsilon}$, where $C$ is consumption, $\rho$ is the rate of time preference, $\varepsilon$ is the elasticity of intertemporal substitution and $r$ is the interest rate.

\section{The Decentralized Problem}

The decentralized problem is to find the market allocation of output in each period between consumption, investment and research. A decentralized equilibrium in the model is an allocation that is compatible with household utility maximization subject to a standard intertemporal budget constraint, profit maximization in all three sectors given the laws of motion for capital and technology, as well as market clearing on the goods and factor markets.

Firms in the competitive final good sector take intermediate goods' prices as given and demand quantities of the intermediate goods such that price equals marginal product: $p_{i t}=$ $A_{i t} F_{1}\left(x_{i t}, L\right) \forall i \forall t$. In the intermediate goods sectors, goods are produced by a monopolist who maximizes profits: $\pi_{i t}=A_{i t} F_{1}\left(x_{i t}, L\right) x_{i t}-\zeta_{t} K_{i t}$, where $K_{i t}=A_{i t} x_{i t}$. He takes as given the user costs of capital $\zeta_{t}=r_{t}+\delta$ which consist of the interest rate $r$ and the rate of depreciation $\delta$. He does not take prices as given but faces the marginal price schedule from the final good sector. Thus, he will supply a quantity such that marginal revenue (scaled by the productivity level) $F_{1}\left(x_{i t}, L\right)+x_{i t} F_{11}\left(x_{i t}, L\right)$ equals the (scaled) marginal cost $\zeta_{t}$. Because $K_{i t}=A_{i t} x_{i t}$, the 
productivity parameter $A_{i t}$ enters both revenue and costs. Hence all monopolists in the different sectors will produce the same quantity $x_{i t}=x_{t}$. This simplifies the equilibrium condition on the capital market: $x_{t}=k_{t} L$, where $k_{t}=\frac{K_{t}}{A_{t} L}$ is the capital stock per effective unit of labor and $A_{t}=\int_{0}^{1} A_{i t} d i$ is the average productivity parameter. Furthermore, the aggregate production function simplifies: $Y_{t}=F\left(K_{t}, A_{t} L\right)$, or in intensity notation $y_{t}=f\left(k_{t}\right)$. The "marginal revenue equals marginal cost" condition for the monopolist can then be rewritten: $R\left(k_{t}\right)=r_{t}+\delta=\zeta_{t}$, where $R\left(k_{t}\right)=F_{1}\left(k_{t}, 1\right)+k_{t} F_{11}\left(k_{t}, 1\right)$ is the productivity adjusted marginal revenue of the monopolist. It is assumed that this marginal revenue decreases in the capital stock. Thus profits in the intermediate goods sector can be expressed as a function of the capital stock: $\pi_{i t}=A_{i t} \pi\left(k_{t}\right) L$, where $\pi\left(k_{t}\right)=F_{1}\left(k_{t}, 1\right) k_{t}-\left[F_{1}\left(k_{t}, 1\right)+k_{t} F_{11}\left(k_{t}, 1\right)\right] k_{t}=-k_{t}^{2} F_{11}\left(k_{t}, 1\right)$. Equilibrium profits increase in the equilibrium capital stock $k$.

In the research sectors, productivity-adjusted research input in each sector $n_{i t}=\frac{N_{i t}}{A_{t}^{\text {max }}}$ is chosen in order to maximize expected profits. Profits in case of a successful innovation are $\pi_{i t}=\pi_{t}=A_{t}^{\max } \pi\left(k_{t}\right) L$. Thus the sectors will choose $n_{i t}=n_{t}$ such that marginal costs equal expected marginal revenue, where $V_{t}$ denotes the expected revenue: $A_{t}^{\max }=\lambda V_{t}$ with $V_{t}=$ $\int_{t}^{\infty} e^{-\int_{t}^{\tau}\left(r_{s}+\lambda n_{s}\right) d s} A_{t}^{\max } \pi\left(k_{\tau}\right) L \quad d \tau$. This condition can be simplified to yield the familiar research arbitrage equation: $1=\lambda \frac{\pi\left(k_{t}\right) L}{r_{t}+\lambda n_{t}}$. Using the equilibrium interest rate as a function of $k$, this expression defines a monotonically increasing relationship: $n_{t}=\hat{n}\left(k_{t}\right)$ with $\hat{n}^{\prime}\left(k_{t}\right) \geq 0$.

In a steady state, the capital market equilibrium and the research arbitrage equation can be simplified (using the household Euler equation and the equilibrium growth rate $g=\sigma \lambda n$ ):

$$
\begin{aligned}
& R(k)=\rho+\varepsilon \sigma \lambda n+\delta, \\
& 1=\lambda \frac{\pi(k) L}{\rho+(\varepsilon \sigma+1) \lambda n} .
\end{aligned}
$$

The capital market equilibrium defines a decreasing function and the research arbitrage equation defines an increasing function in the $k-n$ space.

\section{The Social Optimum}

We now derive the social optimum. A social planner chooses consumption $C_{t}$, capital investment $I_{t}$ and research $N_{t}$ to maximize the utility of a representative household, $U=\int_{0}^{\infty} e^{-\rho t} u\left(C_{t}\right) d t$ with $u\left(C_{t}\right)=\frac{C_{t}^{1-\varepsilon}-1}{1-\varepsilon}$. The planner has to ensure final good market clearing: $Y_{t}=\int_{0}^{1} A_{i t} F\left(x_{i t}, L\right) d i=$ $C_{t}+I_{t}+N_{t}$ as well as capital market clearing: $K_{t}=\int_{0}^{1} A_{i t} x_{i t} d i$ and take into account the laws of motion for capital accumulation $\dot{K}_{t}=I_{t}-\delta K_{t}$ and technology accumulation $\dot{A}_{t}=\lambda \frac{N_{t}}{A_{t}^{\text {max }}} \sigma A_{t}$. The problem can be simplified by noting that - as in the private solution - all sectors produce the same amount of the intermediate goods (which ensures an efficient production at any point in time). Thus, an equilibrium on the capital market requires $x_{t}=k_{t} L=\frac{K_{t}}{A_{t} L} L$ and the production function simplifies to $Y_{t}=F\left(K_{t}, A_{t} L\right)$. Furthermore, as in the laissez-faire solution [see Howitt and Aghion (1998), page 116 and footnote 17], it can be shown that in the social optimum: $\frac{A_{t}}{A_{t}^{\text {max }}}=\frac{1}{1+\sigma}$. Therefore, the law of motion for technology accumulation can be written as $\dot{A}_{t}=$ $\lambda N_{t} \frac{\sigma}{1+\sigma}$. Inserting the condition for an equilibrium on the final goods market into the law of motion for capital accumulation, we face a standard two-dimensional optimal control problem with state variables $K_{t}, A_{t}$ and control variables $C_{t}, N_{t}$. The Hamiltonian is given by:

$$
H=\frac{C_{t}^{1-\varepsilon}-1}{1-\varepsilon}+\eta_{t}\left[F\left(K_{t}, A_{t} L\right)-C_{t}-N_{t}-\delta K_{t}\right]+\mu_{t}\left[\lambda N_{t} \frac{\sigma}{1+\sigma}\right] \text {. }
$$


The first order conditions are: $\frac{\partial H}{\partial C_{t}}=C_{t}^{-\varepsilon}-\eta_{t}=0$ which leads to $\eta_{t}=C_{t}^{-\varepsilon}$ and $\dot{\eta}_{t}=-\varepsilon \frac{\dot{C}_{t}}{C_{t}} \eta_{t}$. This is the familiar condition that the marginal gain of an investment in $K$ weighted with the shadow price $\eta_{t}$ equals the marginal utility of consumption today. Furthermore, $\frac{\partial H}{\partial N_{t}}=0-\eta_{t}+\mu_{t} \lambda \frac{\sigma}{1+\sigma}=0$ which leads to $\mu_{t}=\frac{\eta_{t}}{\lambda \frac{\sigma}{(1+\sigma)}}$ and $\dot{\mu}_{t}=\frac{\dot{\eta}_{t}}{\lambda \frac{\sigma}{(1+\sigma)}}$. This condition says that the gains from an investment in $K$ equal the gains of an investment in $A$. Next we calculate the multipliers $\mu_{t}$ and $\eta_{t}$ using the Euler equations: $\dot{\eta}_{t}=\rho \eta_{t}-\eta_{t} F_{1}\left(K_{t}, A_{t} L\right)+\delta \eta_{t}$ which leads to:

$$
\frac{\dot{C}_{t}}{C_{t}}=\frac{F_{1}\left(k_{t}, 1\right)-(\rho+\delta)}{\varepsilon} .
$$

The only difference to the Euler equation in the decentralized problem is that the interest rate is replaced by the marginal product of capital. Furthermore, $\dot{\mu}=\rho \mu-\eta F_{2}\left(K_{t}, A_{t} L\right) L$ which, by inserting the expressions for $\mu$ and $\dot{\mu}$ and dividing by $\eta_{t}$ gives us:

$$
\frac{\dot{C}_{t}}{C_{t}}=\frac{\lambda \frac{\sigma}{1+\sigma} F_{2}\left(K_{t}, A_{t} L\right) L-\rho}{\varepsilon} .
$$

This equation differs from (3.1) by replacing the (social) marginal product of capital with that of the factor technology. The system of equations $(3.1,3.2)$ describes the social optimum.

\section{Welfare Properties of the Steady State}

We now compare the laissez-faire steady-state and social planner solution. In the planner's problem, as in the private steady state, the growth rate of consumption will be $g=\lambda n \sigma$. Furthermore, we denote $\pi^{*}\left(k_{t}\right)=F_{2}\left(k_{t}, 1\right)$. Dropping time indices, the system of equations $(3.1,3.2)$ then simplifies. Table 1 summarizes the two solutions (equations $\left(\hat{K}, \hat{N}\right.$ versus equations $\left.\left(K^{*}, N^{*}\right)\right)$ that differ due to three classes of effects.

\begin{tabular}{|c|c||c|c|}
\hline & laissez faire solution & social optimum & \\
\hline$\hat{K}$ & $F_{1}(k, 1)+k F_{11}(k, 1)=\rho+\varepsilon \sigma \lambda n+\delta$ & $F_{1}(k, 1)=\rho+\varepsilon \sigma \lambda n+\delta$ & $K^{*}$ \\
\hline$\hat{N}$ & $1=\lambda \frac{\pi(k) L}{\rho+(\varepsilon \sigma+1) \lambda n}$ & $1=\lambda \frac{\pi^{*}(k) L \sigma \frac{1}{1+\sigma}}{\rho+\varepsilon \sigma \lambda n}$ & $N^{*}$ \\
\hline
\end{tabular}

Table 1: Laissez-faire steady state solution and social optimum

The first class of effects is related to the distribution of the period flow of social surplus to the production factors. Recall that the decentralized economy faces the problem (due to increasing returns to scale) that total production $F(K, A L)$ is insufficient to remunerate all three factors $K, A, L$ by their marginal product.

Consider the following decomposition of the productivity adjusted output $F(K, A L) / A=$ $F(k, 1) L=F_{1}(k, 1) k L+F_{2}(k, 1) L$ into the factor incomes in the laissez-faire solution:

$$
F(k, 1) L=\underbrace{\left(F_{1}(k, 1)+k F_{11}(k, 1)\right)}_{\text {Capital Income }} k L \underbrace{\underbrace{-F_{11}(k, 1) k^{2} L}_{\pi(k) L}}_{\text {Profits }}+\underbrace{\underbrace{F_{2}(k, 1)}_{\text {w }} L}_{\text {wage income }}
$$

Profit income $\pi\left(k_{t}\right) L$ serves for the remuneration of research in the laissez-faire solution. It shows up in the numerator of the N-equations in table 1. The social gains $\pi\left(k_{t}\right)^{*} L$ in table 1 correspond to the marginal productivity of technology $\frac{\partial F(K, A L)}{\partial A}=F_{2}\left(k_{t}, 1\right) L$. This establishes the principal 
dilemma: Whereas the quantity of $\mathrm{R} \& \mathrm{D}$ should be determined by the marginal productivity of innovation it is actually determined by the part of the marginal productivity of capital that accrues as profits. Thereby, the degree of monopoly power determines the partition of the marginal product of capital into capital income and profits.

Some intuition whether this distortion induces too much or too little R\&D can be obtained by highlighting two distinct effects. We can represent them by describing the marginal productivity of technology in terms of output and the marginal productivity of capital: $F_{2}(k, 1)=$ $F(k, 1)-k F_{1}(k, 1)$. Then private and social gains of innovation appear in the form "revenue minus costs": $\pi(k) L=\left[F_{1}(k, 1) k-\left(F_{1}(k, 1)+k F_{11}(k, 1)\right) k\right] L$ and $\pi^{*}(k) L=\left[F(k, 1)-F_{1}(k, 1) k\right] L$. First, private and social revenue differ. The planner takes into account total output $F(k) L$, whereas the monopolist can only appropriate total output minus consumer surplus $F_{1}(k) k L$. This appropriability effect tends to generate too little research under laissez-faire. Second, private and social costs differ, since the monopolist's marginal revenues are lower than the marginal revenue in the planner's solution. In equilibrium, marginal revenue equals marginal cost. For any given capital input, the monopolist is ready to pay only $\left(F_{1}(k, 1)+k F_{11}(k, 1)\right) k L$ to capital owners. However, it would be socially optimal to pay the marginal product $F_{1}(k, 1) k L$ (=capital income plus profits). This monopoly distortion effect generates too much private research.

The monopoly distortion effect can also be found in the K-equations: consider the remuneration to capital $r(k) k L$. The monopolist's gain from the lower capital cost is borne by the household supplying capital whose gross return will be lower than in the optimal solution. The effect will induce too little capital accumulation and increases with monopoly power. This effect is absent in Aghion and Howitt (1992) - simply because of the absence of capital.

The second class of effects describes spillovers across sectors. It reflects the fact that a successful researcher in any given sector $i$ invents a technology $A^{\text {max }}$ independently of his own current technology $A_{i}$. The technology $A^{\max }$ of course enters a researcher's cost-benefit calculation when calculating his optimal research spending $N$ or research intensity $n=N / A^{\text {max }}$. The research costs incurred by a social planner are also $N$. However, the planner is not interested in the effects of an additional investment in research on profits. Recall that profits are proportional to the leading edge technology $A^{\max }$. The planner cares about the effects of additional research on the average technology level $A$. In a steady state, the gap between average and leading edge technology are reflected by the term $\frac{1}{1+\sigma}$ in the numerator of the $N^{*}$-equation. In a steady state, this term equals $\frac{A}{A^{\text {max }}}$. We call this effect a cost-benefit gap effect because the cost-benefit calculation of the planner and a private researcher differ due to the gap between leading edge and average technology. The magnitude of this effect is small if the average technology does not differ much from the leading-edge technology, i.e if $\sigma$ is small. The cost-benefit gap leads to excessive private research. This effect is absent in Aghion and Howitt (1992) because the research intensity does not depend on the leading edge technology.

The third and last class of effects describes intertemporal effects. First, the $\sigma$ in the numerator of equation $N^{*}$ describes the well known business stealing effect from Aghion and Howitt (1992) that we refer to as active business stealing effect, as we explain now. The social planner considers the incremental surplus of an innovation relative to the old technology (and not the size of the innovation per se). This is reflected by the factor $\sigma$, which can be interpreted as a measure of the impact of each innovation on the stock of public knowledge. A successful researcher becomes monopolist, on the other hand, and gains at the cost of his predecessor without compensating him for the basis of knowledge on which the new monopolist builds. By innovating he actively steals the previous monopolist's profits (business). This is most obvious in the extreme case of 
$\sigma=0$ where an innovator drives out his predecessor without generating progress. Active business stealing is a "carrot" [Jones and Williams (2000)] for innovators and thus the creative part of creative destruction. Note that there is a difference between this model and Aghion and Howitt (1992) concerning the active business stealing effect. In Aghion and Howitt (1992) $\sigma$ could be interpreted as the size of an innovation. The size matters for the private monopolist because he appropriates not only the old monopolist's profits but also the gains from a discontinuous jump (from $A_{t}$ to $A_{t+1}$ ) in the stock of knowledge due to an innovation. The reason for this is that he incurs research costs based on the old technology (which is the stock of knowledge at the time he carries out research) but earns benefits (conditional on innovating) based on the new technology (invented by himself). In Howitt and Aghion (1998) no such discontinuous jump occurs. A researcher calculates with the same $A_{t}^{\max }$ both on the cost and benefit side. The reason for this is the assumption of a continuously growing leading-edge technology which is used as research input: recall that the research intensity is $n=N / A^{\max }$. This difference to Aghion and Howitt (1992) implies that the active business stealing effect is ambiguous in this model (whereas it generates too much research in Aghion and Howitt (1992)): for $\sigma<1$ there is too much research under laissez-faire, for $\sigma>1$ the opposite is true, and for $\sigma=1$ the laissez-faire solution is socially optimal (as far as this effect is concerned). From a social point of view, a high research productivity $\sigma$ makes a high research intensity desirable. But the monopolist ignores technological progress $\sigma$. For $\sigma<1$ the effect induces too much private research.

Another intertemporal effect arises because the social and private discount rates differ. In Aghion and Howitt (1992), this effect was called intertemporal spillover effect. We will decompose the effect into 3 subeffects, two of which are present in both Aghion and Howitt (1992) and Howitt and Aghion (1998), and one is new in Howitt and Aghion (1998).

First, the research firm discounts profits at a rate higher than the interest rate $\rho+\varepsilon \sigma \lambda n$. The reason for this is that it takes into account the Poisson probability $\lambda n$ of losing its monopoly. This effect is the destructive part of creative destruction. We call this passive business stealing effect because the monopolist fears that his profits are stolen by a successive innovator. This effect is the backside of the active business stealing effect and is already present in Aghion and Howitt (1992). It constitutes a disincentive or "stick" [Jones and Williams (2000)] for innovators.

The planner considers this destructive effect $+\lambda n$, but also considers that the destroyed old profits are overcompensated by the larger profits of the new innovator $-(1+\sigma) \lambda n$. This fact leads to a social discount rate that is lower than the interest rate in the Aghion and Howitt (1992) model. This effect is another occurrence of the technology spillover effect, because it reflects the fact that an innovator builds upon and augments the stock of knowledge in the economy generated by innovations in other sectors. In Howitt and Aghion (1998), however, the additional profit of a new innovation has to be used to enlarge the research input in order to support the growth rate of the larger $A^{\text {max }}$. This is due to the assumption (in contrast to Aghion and Howitt (1992)) that the growth rate $g$ is proportional to the research intensity $n=\frac{N}{A^{\text {max }}}$ so that a growing $A^{\max }$ implies a growing $N$ in steady state, which in turn lowers resources available for consumption. We label this new effect consumption dilution effect.

It turns out that in the planner solution the consumption dilution effect exactly offsets the net effect $\sigma \lambda n$ of the technology spillover effect and the passive business stealing effect so that all three cancel out. Concerning the discount rate, the planner thus uses the interest rate and is consequently indifferent towards growth when discounting gains from innovation. Recall that the monopolist considers only the passive business stealing effect. Therefore, the discount rate in the private solution differs from the interest rate by $\lambda n$. 


\section{Discussion and concluding remarks}

We now discuss how the distortions in the private solution relative to the social optimum affect the graphs of the research arbitrage equation and the capital market equilibrium. The monopoly distortion effect tends to generate too little capital accumulation and thus implies that the $K^{*}$ graph is always above the $\hat{K}$ graph. The shift of the $N^{*}$ graph is not uniquely determined. The appropriability and passive business stealing effect generate too little research $\left(\hat{N}\right.$ curve below $N^{*}$ curve), whereas the monopoly distortion effect and the cost-benefit gap effect lead to excessive research under laissez-faire ( $\hat{N}$ curve above $N^{*}$ curve). Finally, the active business stealing effect is a priori ambiguous, depending on the parameter $\sigma$. For the realistic case of a small growth rate of technological progress the effect induces too much research under laissez-faire. For small

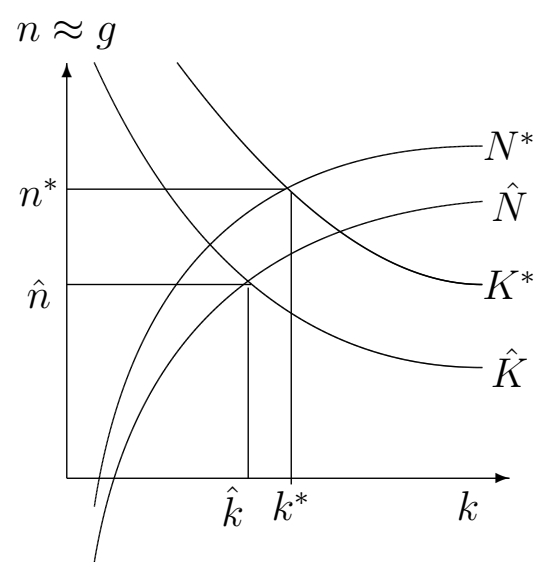

Figure 1: Laissez-faire versus social optimum (example)

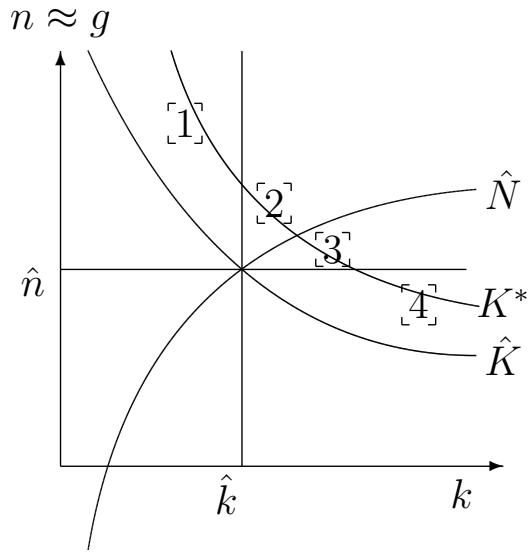

Figure 2: Possible cases for social optimum

distortions of the $N^{*}$ curve relative to the $\hat{N}$ curve, the private solution will have too little capital intensity $\left(\hat{k} \leq k^{*}\right)$ and too little research intensity $\left(\hat{n} \leq n^{*}\right)$. This case is depicted in figure 1 . But for larger distortions, other cases are also possible. Figure 2 characterizes the four possible combinations of too much (too little) capital (research). Sectors 1 to 4 in the figure indicate where the social optimum can lie.

Policy measures which lower capital cost like a capital subsidy accelerate technological progress, because a lower interest rate increases the value of an innovation via higher profits and a lower discount rate. Technically, such policy measures shift the $\hat{K}$ curve to the right. This is an indirect way of subsidizing research and avoids agency problems of a direct research subsidy [see Howitt and Aghion (1998) for a discussion]. The welfare effects of such a subsidy are unambiguously positive if the optimum is in sectors 2 or 3 in figure 2 . Then private capital and research intensity are moved towards the social optimum. However, if the economy is in sector 1 where the economy overaccumulates physical capital (dynamic inefficiency), the welfare effects of a subsidy are not clear a priori because the capital stock is further enlarged (which is undesirable) but the research intensity increases (which is desirable). An analogous argument holds for an optimum in sector 4 . There, a capital subsidy leads to a larger capital stock (which is positive in that case). On the other hand, the research intensity increases although in this sector research is already excessive. Neither case can be ruled out on theoretical grounds. 


\section{References}

Aghion, Philippe and Peter Howitt (1992), A Model of Growth through Creative Destruction, Econometrica 60, 323-351.

Jones, Charles and John Williams, Too Much of a Good Thing? The Economics of Investment in R and D, Journal of Economic Growth 5, 65-85.

Howitt, Peter and Philippe Aghion (1998), Capital Accumulation and Innovation as Complementary Factors in Long-Run Growth, Journal of Economic Growth 3, 111-130. 